\title{
Functional relationship between harp seal body condition and available prey in the Barents Sea
}

\author{
Tor Arne Øigård ${ }^{1, *}$, Ulf Lindstrøm ${ }^{1}$, Tore Haug ${ }^{1}$, Kjell Tormod Nilssen ${ }^{1}$, \\ Sophie Smout ${ }^{2}$
}

\author{
${ }^{1}$ Institute of Marine Research, PO Box 6404, 9294 Tromsø, Norway \\ ${ }^{2}$ Sea Mammal Research Unit, Scottish Oceans Institute, University of St. Andrews, St. Andrews, Fife KY16 8LB, UK
}

\begin{abstract}
The Barents Sea ecosystem has undergone substantial ecological fluctuations over the past $40 \mathrm{yr}$, including large variations in the abundance of capelin Mallotus villosus, herring Clupea harrengus, krill Thysanoessa sp. and Meganyctiphanes norvegica, polar cod Boreogadus saida, and Atlantic cod Gadus morhua. There is evidence to suggest that harp seals Pagophilus groenlandicus have responded to these changes. The current study analysed the relationships between harp seal body condition, environmental variables and the biomass of major harp seal prey. Harp seal body condition was estimated from samples taken in the southeastern Barents Sea during spring from 1992 to 2011. Body condition of juveniles and adults varied between years, improving from 1992 until 2001 and later deteriorating, with weakest condition in 2011. We investigated covariates that might explain such interannual variation. Significant relationships were found between harp seal blubber thickness and prey abundances. High abundances of capelin, polar cod and Atlantic cod had a negative impact on condition, whereas high abundance of krill had a positive impact. Environmental covariates did not improve the models, probably because these were strongly correlated with prey abundance. We also found a correlation between pup production and blubber thickness, indicating that observed declines in pup production may be associated with decreased body condition of the seals. We further show that competitive interactions in the food web (e.g. competition between harp seals and some of their prey for shared resources, such as krill) may result in unexpected negative predator-prey relationships. This has implications for predator breeding success and population dynamics.
\end{abstract}

KEY WORDS: Harp seal · Predator-prey $\cdot$ Body condition $\cdot$ Barents Sea $\cdot$ Prey availability $\cdot$ Prey quality $\cdot$ Generalised additive model

\section{INTRODUCTION}

The ability to maximise energy intake during productive periods and survive during lean times is an important adaptation for marine mammals living in the Barents Sea (Kovacs et al. 2009). The seasonal variation in prey energetic content and availability causes the body mass of marine mammals feeding in the Arctic to vary substantially through the year and a regular seasonal pattern of deposition of energy reserves as fat in the subcutaneous blubber layer is particularly evident in harp seals (Timoshenko 1995, Chabot et al. 1996, Nilssen et al. 1997).
Harp seals use different areas of the ocean at different times of the year and their diet varies in time and space. Fish dominate their diet in the southern Barents Sea, whereas various crustacean species (mainly krill and amphipods Themisto sp.) dominate their diet along the drift ice in the north (Lydersen et al. 1991, Nilssen et al. 1995a,b, Lindstrøm et al. 1998). The seals lose fat during the breeding (whelping, lactation, mating) and moulting periods (March to June), while their body condition improves during summer as the availability of energy-rich prey increases. The seals build up energy reserves during the summer and autumn, reaching a peak in October 
to November; thereafter their condition generally remains stable until breeding in March (Nilssen et al. 1997).

There is also good evidence to suggest that, in addition to this seasonal variation, there is interannual variation in the body condition of harp seals, resulting from changes in prey abundance (Timoshenko 1995, Chabot et al. 1996, Nilssen et al. 1997, 2001). During recent decades the abundance of capelin, herring, krill and polar cod has fluctuated substantially in the Barents Sea (Nakken 1994, Gjøsæeter et al. 2009a). The causes of these changes are complex, because they arise from interactions between species and the environment, and also from fishing (e.g. Halpern et al. 2008, Johannesen et al. 2012). Several authors suggested that inter-annual variation in Barents Sea temperature accounts for much of the variation in Atlantic cod recruitment (Ottersen et al. 1994, Ottersen \& Sundby 1995, Bogstad et al. 2013). Temperature conditions in the southern and central Barents Sea are to a large extent determined by the strong influences of Atlantic water flowing in from the southwest and mixing with Arctic water (Dippner \& Ottersen 2001), so that the Barents Sea is warm compared with other areas at the same latitude (Johannesen et al. 2012). Other oceanographic processes in the Barents Sea, such as water cooling and ice formation (Ozhigin et al. 2011), and the narrow and strong coastal current entering the Barents Sea close to the Norwegian coast also have important effects on fish stocks (Loeng et al. 1997).

The mean annual temperatures in the Barents Sea during the years 2004 to 2007 were higher than those recorded in the 1990s (Eriksen \& Dalpadado 2011). Since the late 1970s/early 1980s, the temperature in the Barents Sea has increased by $\sim 1.5^{\circ} \mathrm{C}$ (Skagseth et al. 2008) and, in addition, sea ice extent has decreased by $10 \%$ (Sorteberg \& Kvingedal 2006). It is expected that this will have consequences on the distribution and abundance of the krill populations. This is important, since krill play a major role in the Barents Sea ecosystem by acting as a link between phytoplankton and the higher trophic levels, such as capelin and Atlantic cod (Eriksen \& Dalpadado 2011).

Observations made in the Barents Sea indicated that poor condition of juvenile and adult seals could be linked to reduced recruitment to the stock (Nilssen et al. 1998, 2001). Russian aerial surveys, carried out to estimate the pup production of harp seals in the White Sea in 2004, 2009 and 2010, indicated a major decline, compared to estimates from previous surveys (ICES 2011a). Could reduced prey abundance have contributed to this decline? To address the hypothesis that prey abundance changes affect the seal population through effects on condition and life history parameters, we used records from a longitudinal Norwegian sampling program, conducted during April and May in 1992 to 2011 onboard Norwegian sealers, operating in the southeastern Barents Sea (the East Ice). Scientists have used these opportunities to collect body condition data from a large number of juvenile and adult harp seals.

The main objectives of our study were (1) to analyse possible year-to-year variations in body condition of harp seals in the Barents Sea during the moulting season, (2) to explore the relationship of harp seal body condition to available prey biomass and environmental changes, through environmental indices, such as the North Atlantic Oscillation (NAO) index, Kola Peninsula temperature data and the summer open water (SOW) index, and (3) to investigate whether the observed decline in pup production was associated with changes in body condition of the seals.

\section{MATERIALS AND METHODS}

\section{Data}

Harp seal condition

The data used in this study were from 2495 harp seals sampled during commercial sealing operations in the East Ice between 1992 and 2011 (Figs. 1 \& 2). This sampling took place during the moulting season (March to May). Most of the sampling in 1992 and between 1996 and 2000 was carried out during the first half of April, whereas in 1995 and 2001, most samples were taken in late and early March, respectively (Fig. 2). In 2006 and 2011 the seals were sampled in the beginning of May. Only 1-yr old and older seals (1+ animals) were sampled in 2011.

Another data set of 385 harp seals was obtained from research surveys in the Barents Sea in the years 1991, 2004, 2005 and 2006. The data from these surveys were collected later in the season (June and July) when the body condition of the seals is at its worst (Nilssen et al. 1997). Because these animals were sampled later in the year than those from commercial sealing, the data were not used in our statistical modelling. However, since they represent the lowest level of condition observed for the harp seals during the year, they are included in Figs. 1 \& 2 for comparison with the data obtained from commercial sealing carried out in the moulting season. 


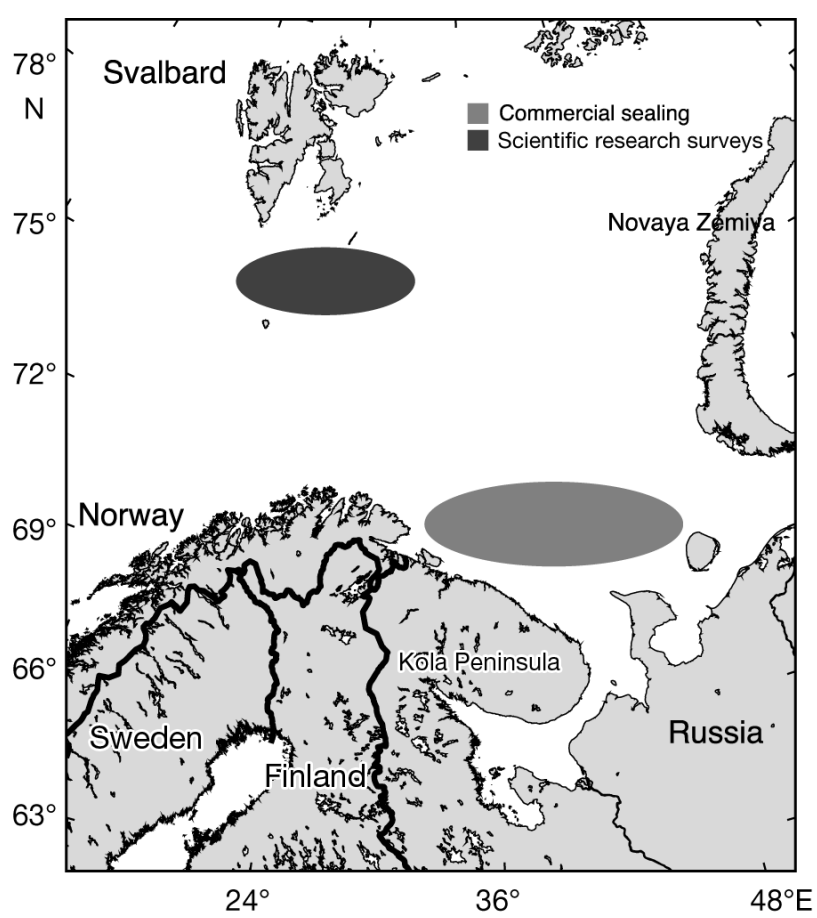

Fig. 1. Pagophilus groenlandicus. Sampling locations in the southeastern (East Ice) and northwestern Barents Sea in the years 1991 to 2011. Samples from 1991, 2004, 2005 and 2006 were taken during scientific research surveys, while all others were from commercial sealing operations

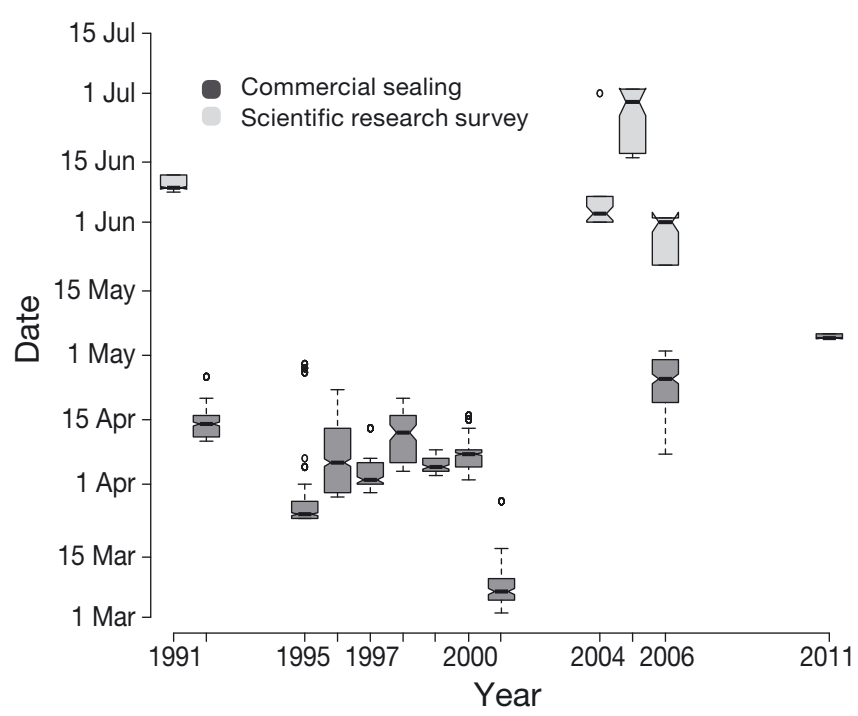

Fig. 2. Pagophilus groenlandicus. Temporal distribution of harp seal sampling in the Barents Sea from 1991 to 2011. Horizontal bar: median (50th percentile); box: interquartile range (IQR, 25th to 75th percentile); whiskers: last values within $1.5 \times$ IQR of the lower and higher quartile; circles above/below whiskers: seals sampled much later/earlier than the main sampling period of each year; box 'waist': rough guide to the significance of differences in the medians (if 2 waists do not overlap, there is a statistically significant difference between the medians)
All measurements followed the procedure described in Nilssen et al. (1997). Seals were weighed to the nearest kg. No corrections of body mass were made for the weight of lost blood, following the killing by shooting and subsequent bleeding of the seals. Standard body length of all seals was measured to the nearest $\mathrm{cm}$ in a straight line from the tip of the snout to the tip of the tail, with the animal lying on its back. Dorsal blubber thickness in a knife-cut at the midline between the front flippers was measured (excluding the thickness of the skin) to the nearest $\mathrm{mm}$.

Prey species

The abundances of capelin, herring, polar cod, Atlantic cod, krill, saithe Pollachius virens, haddock Melanogrammus aeglefinus and amphipods were used as covariates in this study to explore the effect of available prey biomass on harp seal blubber thickness. The prey species were selected based on knowledge from previous studies of harp seal diets in the Barents Sea (Nilssen et al. 1995a,b, Lindstrøm et al. 1998, 2013). The biomass data were taken from fish stock assessments and published estimates (Gjøsæter et al. 2009a, ICES 2010, 2011b, Eriksen \& Dalpadado 2011). The Atlantic cod data were split into 2 groups: biomass of 1- and 2-yr old Atlantic cod, and biomass of 3-yr old Atlantic cod and older. Although harp seals may feed on large prey, previous diet studies suggest they feed almost exclusively on smaller size groups (<30 cm; Lindstrøm et al. 2013) corresponding to 1- to 2-yr old Atlantic cod. It therefore seems likely that small Atlantic cod (aged 1 to 2 yr) act as prey for harp seals, while large Atlantic cod, aged 3 yr and older (3+ age), may act as competitors (e.g. Bogstad et al. 2000). A covariate aggregating all biomass data on Atlantic cod was also explored.

\section{Environmental variables}

The NAO index, Kola Peninsula temperature data and the SOW index (Ozhigin et al. 2011, Johannesen et al. 2012) were used in this study to explore the effect of environmental changes on harp seal blubber thickness. These are indices representing the atmospheric influences, ice coverage and sea temperature in the Barents Sea. The NAO index is the dominant signal of inter-annual variability in atmospheric circulation for northern and central Europe (e.g. Lamb \& Peppler 1987, Hurrell \& Deser 2010) and is defined as 
the difference in the sea level air pressure anomalies between the Azores high and the Icelandic low. The annual NAO index was used as a measure of the atmospheric influence (downloaded from www.cgd. ucar.edu/cas/jhurrell/indices.html). The Kola Peninsula temperature data are vertically integrated temperature values that were sampled by the Knipovich Polar Research Institute of Marine Fisheries and Oceans in Murmansk, Russia (www.pinro.ru). The SOW index is a quantitative area-based measure of the variation in the ice-free area north of $79^{\circ} \mathrm{N}$, integrated over summer. A high value corresponds to a large fraction of open water and an index equal to 0 means that the ice edge is south of $79^{\circ} \mathrm{N}$ throughout summer (Johannesen et al. 2012). These abiotic variables could affect the condition of seals either directly (e.g. due to costs of maintaining body temperature) or through mediating changes in the abundance, distribution, condition and accessibility of prey.

\section{Statistical analyses}

Box plots were used to display the distribution of various variables. Generalized additive models (GAMs) provide a powerful and flexible statistical tool for modelling non-linear relationships (Wood 2006). To test whether the significant drop in the pup blubber thickness in 2001 and the drop in the blubber thickness of the 1+ group in 2006 and 2011 could be a result of the later date of sampling, a GAM was fitted with blubber thickness modelled as a function of the covariates length, date (expressed as days elapsed since 1 March) and year. A normal error distribution and identity link function were used. For the juvenile and adult animals (1+group) the starting model was:

$$
\begin{aligned}
\text { Blubber thickness } & =\alpha+\mathrm{s}(\text { length }): \mathrm{sex}+\mathrm{s}(\text { date }) \\
& +\mathrm{s}(\text { year })+\varepsilon
\end{aligned}
$$

where $\mathrm{s}(\cdot)$ is an estimated smooth function of the covariates, $\alpha$ is the intercept and error $\varepsilon$ is assumed to be normally distributed with mean 0 and standard deviation $\sigma$. The notation $\mathrm{s}($ length):sex means that a smoother is applied to the length of each sex. This modelled the blubber thickness as a function of length differently between males and females. A similar model was constructed for the blubber thickness of pups, but in this case preliminary analyses showed no significant difference between the sexes. Therefore, the data for pups were pooled and the interaction term between length and sex was dropped.
Next, the year effect was replaced by available prey biomass data and environmental variables to explore how variation in prey biomass and environment affects the condition of the seals:

$$
\begin{aligned}
& \text { Blubber thickness }=\alpha+\mathrm{s}(\text { length }): \mathrm{sex}+\mathrm{s}(\text { date }) \\
& +\sum_{i} \mathrm{~s}\left(\text { prey }_{i}\right)+\sum_{j} \mathrm{~s}\left(\text { environ }_{j}\right)+\varepsilon
\end{aligned}
$$

where $\operatorname{prey}_{i}$ is the biomass of a prey type, which may be capelin, herring, polar cod, Atlantic cod, krill, saithe, haddock or amphipods. The environ ${ }_{j}$ covariate is one of the environmental variables, i.e. either the NAO index, Kola Peninsula temperature data or the SOW index.

Time lags of 0,1,2 and $3 \mathrm{yr}$ were used on the prey biomass and environmental variables. For the different time lags, all possible combinations of the biomass and environmental covariates were explored. Also, interaction terms between the prey biomass covariates were explored, i.e. 2-dimensional responses such as s(capelin, Atlantic cod). Fig. 3 shows the most important prey covariates and all environmental variables, along with the mean blubber thickness of the 1+ animals. Dashed vertical lines are used for

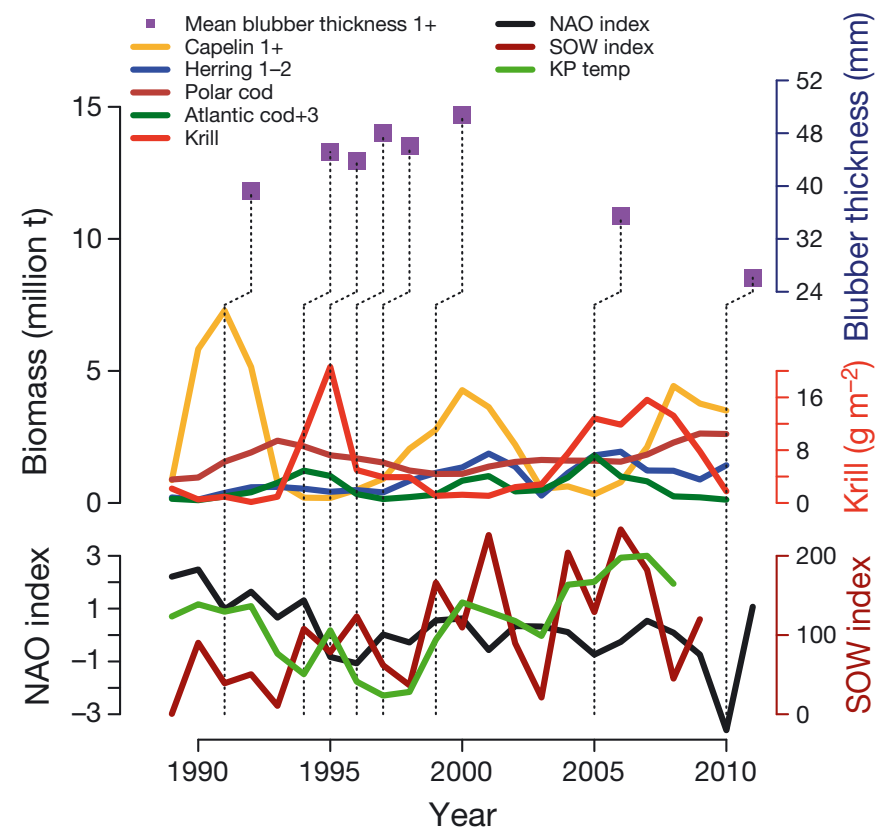

Fig. 3. Abundance estimates (biomass) of capelin Mallotus villosus, herring Clupea harrengus, polar cod Boreogadus saida, Atlantic cod Gadus morhua and krill Thysanoessa sp. and Meganyctiphanes norvegica in the period 1990 to 2010, along with mean blubber thickness, the North Atlantic Oscillation (NAO) index, the summer open water (SOW) index and the Kola Peninsula temperature data (KP temp: range $3.6-5.1^{\circ} \mathrm{C}$ in this time period). Dashed lines indicate that prey and environmental data used in the analyses have a 1 yr time lag relative to the blubber thickness data 
visual aid to relate the measured blubber thickness with available prey biomass with a time lag of $1 \mathrm{yr}$. The alternating peaks of capelin and krill in this figure suggest that there is a negative correlation between these species.

The explanatory variables were checked for colinearity by visual inspection of pairwise scatterplots of covariates, and through calculating Pearson correlations and variance inflation factors (VIFs; Zuur et al. 2010). A high VIF for a covariate means that most of the variation in that particular covariate is explained by all other covariates and therefore that there is colinearity (Zuur et al. 2010). One strategy for addressing this problem is to sequentially drop the covariate with the highest VIF, recalculate the VIFs and repeat this process until all VIFs are smaller than a preselected threshold. As suggested by Zuur et al. (2010), a threshold value of 3 is suitable for ecological data.

Thin plate splines were used as smoothing functions when fitting the GAMs. Due to the number of years sampled, one could either declare the covariates year, prey biomass and environmental variables as nominal variables or continuous variables. If fewer years were sampled, a nominal variable would be an obvious choice, and if more years were sampled one would naturally lean towards a continuous variable. As suggested by Ruppert et al. (2003), Wood (2006) and Zuur (2012), we decided to treat the year-variable, biomass data and climatic indices as continuous variables, starting with a high degree of smoothing, i.e. 3 degrees of freedom each. If the residuals from these estimated smoothed functions contained patterns, we increased the degrees of freedom and repeated this process until no patterns were found in the residuals. Model selection was evaluated on the basis of Akaike's information criterion (AIC), with lower values of AIC being preferred (Burnham \& Anderson 2002). In addition, we calculated $\triangle \mathrm{AICs}$, evidence ratios (Anderson 2008) and AIC weights (Johnson \& Omland 2004). The $\triangle \mathrm{AICs}$ are the differences in the AIC scores between each model and the model with the lowest AIC score. Evidence ratios are the ratios between the likelihood of the best model and the likelihood of the alternative models (Johnson \& Omland 2004) and are an intuitive way to express the amount of empirical support a model has compared to the support for an alternative model. The AIC weights provide a relative weight of evidence for each model and can be interpreted as the probability that a model is the best model for the observed data, given the candidate set of models (Johnson \& Omland 2004). Pup data and data for the 1+ group were analysed separately.
GAMs were fitted in R ( $\mathrm{R}$ Development Core Team 2009; www.R-project.org) using the mgcv package (Wood 2004, 2006), the $q p c R$ package (Ritz \& Spiess 2008) and the Hmisc package (Harrell 2012). Pearson residuals were plotted against the original explanatory variables to check for residual patterns and the response residuals were inspected for patterns and normality.

In assessing whether the observed decline in pup production was associated with changes in body condition of harp seals, we used pup production estimates from Russian aerial surveys of harp seals in the White Sea from the period 1998-2010 ICES (2011a). Due to poor temporal overlap between data on blubber thickness and pup production estimates, we used the model predictions of the mean blubber thickness obtained from the GAM model in Eq. (1) as a proxy for blubber thickness.

\section{RESULTS}

The measured blubber thickness of pups did not display much year-to-year variation, except for a significant drop in 2001 (Fig. 4A). This drop might be because the samples in 2001 were taken during the Russian hunt of whitecoats in the White Sea in early March, i.e. much earlier in the season than during the other years (Fig. 2).

For the 1+ group, there was evidence of seasonal variation in blubber thickness. Measurements taken in June and July on the research surveys were significantly smaller than the measurements taken during sealing in the March-May period (Fig. 4B). The blubber thickness of the seals seemed to reach a minimum in the June-July period. There was also evidence of inter-annual variation in blubber thickness. Blubber thickness of seals sampled in the period March-May showed an increasing trend from 1992 until 2000 and then decreased significantly in 2006 and decreased further to the lowest condition level in 2011. The blubber of the $1+$ animals was significantly thinner in 2011 than in 2006. However, the samples from 2006 and 2011 were taken later in the season, during a period when the seals are expected to lose weight, than the samples taken between 1992 and 2000 (Fig. 2).

To analyse possible year-to-year variation in the blubber thickness, we used a GAM. Date was included as a covariate. This should remove any potential artifacts in the relationship between blubber thickness and year that might otherwise be created by differences in sampling date between years. Re- 
sults from the model fitted to the pup data (Fig. 5) show that blubber thickness had a close to linear relationship with body length. The estimated degrees of freedom (edf) for the length smoother was

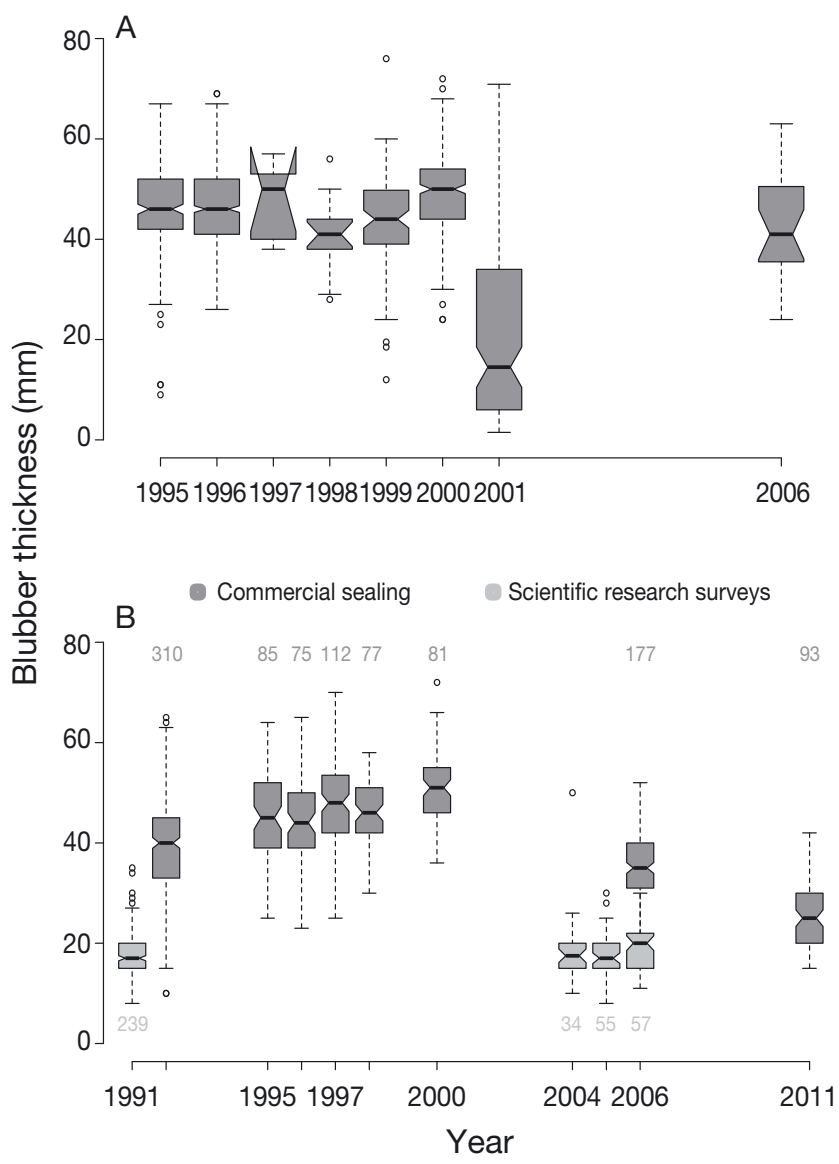

Fig. 4. Pagophilus groenlandicus. Dorsal blubber thickness for (A) harp seal pups sampled in the Barents Sea from 1995 to 2006 and (B) Barents Sea age 1+ yr harp seals in the years 1991 to 2011. Sample size is given above/below each box. Boxplot limits as in Fig. 2
1.8. The model results show a natural increase in the blubber thickness of the suckling pups from the beginning of March to about the end of March, after which the condition of the pups decreased. The condition peak coincided with the termination of the suckling period (edf $=7.1$ ). The year effect showed a minor drop in condition around 1997 to 1998, whereas pup condition appeared to be around the same levels in 1995, and 2000 to 2006. The length, date and year effects were all significant $(p<0.001)$, with an estimated intercept of 44.60 . For the pups no significant difference between sexes was found. The model described $63.5 \%$ of the variation in the blubber thickness measurements of pups. No apparent structure in the residuals was found and 3 degrees of freedom was used for the year covariate.

In the analysis of the 1+ group (Fig. 6), only data sampled on commercial sealing trips during the moulting season in the southeastern Barents Sea were used. A difference between the sexes was found for the body length covariate, i.e. the interaction term 'sex:body length' was significant. The interaction terms 'sex:date' and 'sex:year' were also significant, but since the smoothed estimates obtained showed a similar functional form for both sexes, no interaction term with respect for sex was used on these covariates. The length effect of the males showed an increasing condition of seals up to about $140 \mathrm{~cm}$, with subsequent stabilisation (edf $=3.9$ ). For the females, the condition increased up to about $140 \mathrm{~cm}$, after which the model displayed a significant drop in the condition at lengths of 140 to $160 \mathrm{~cm}$. The condition again increased for females longer than $160 \mathrm{~cm}$ (edf $=5.4$ ). The effect of date on the blubber thickness of $1+$ animals indicated 2 periods of decrease, each followed by a period of stabilisation (edf $=5.5$ ). The condition of the 1+ group increased from 1992, reaching
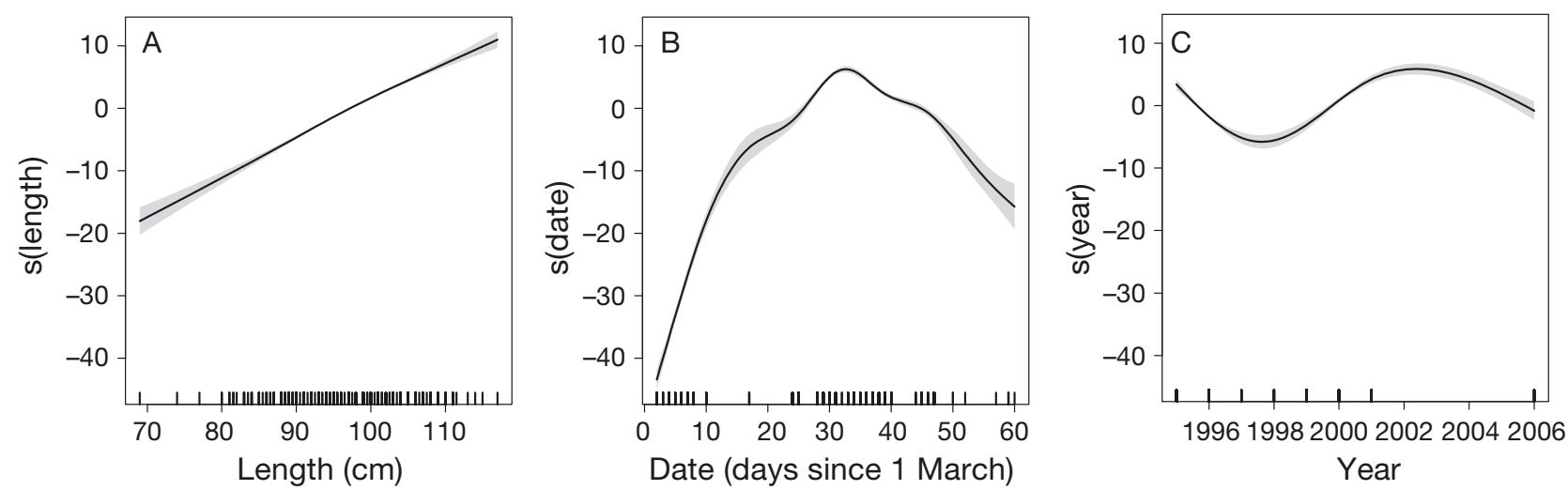

Fig. 5. Pagophilus groenlandicus. Estimated smooth functions (s) showing the relationship between dorsal blubber thickness of harp seal pups in the southeastern Barents Sea and (A) length, (B) date (days elapsed since 1 March) and (C) sampling year. Shaded areas show the $95 \%$ confidence intervals. Black vertical lines on the $x$-axis show presence of data for each covariate 
a peak around 2000, whereafter it dropped significantly in 2006 and 2011. All covariates were significant ( $\mathrm{p}<0.001)$, with an estimated intercept of 40.66 . The model described $49.3 \%$ of the variation in the
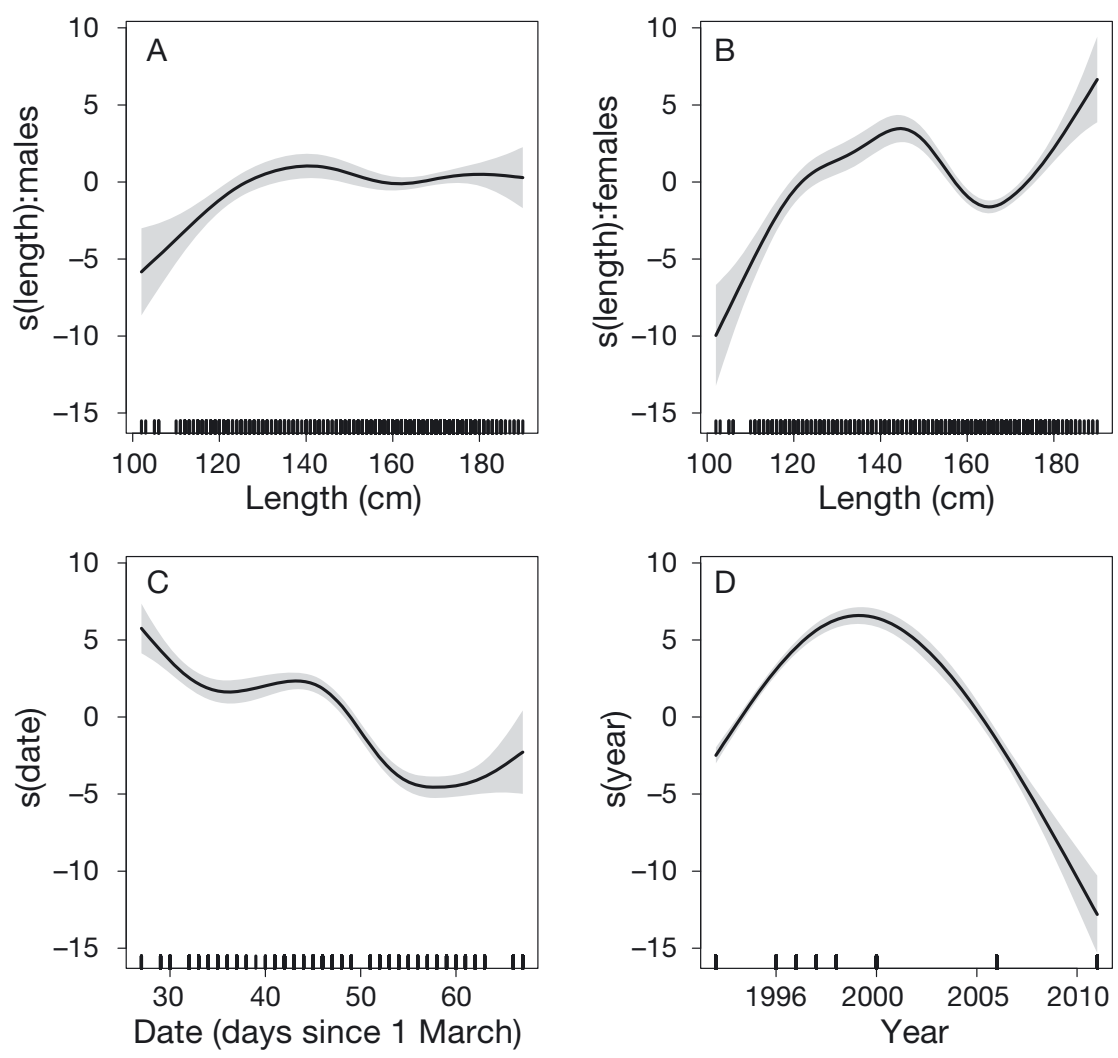

Fig. 6. Pagophilus groenlandicus. Estimated smooth functions (s) showing the relationship between dorsal blubber thickness of age 1+ yr harp seals, taken in the southeastern Barents Sea, and (A) male length, (B) female length, (C) date (days elapsed since 1 March) and (D) sampling year. Shaded areas show the $95 \%$ confidence intervals blubber thickness measurements of the 1+ group and no trends in the residuals were found. Three degrees of freedom was found to be sufficient for the year covariate. We also explored the consequence of dropping year as a covariate. The $\triangle \mathrm{AIC}$ was 171.7 , i.e. indicating a considerable increase of AIC. The deviance explained dropped by $10 \%$. When dropping the date covariate instead, the $\triangle \mathrm{AIC}$ was 87.7 and the deviance explained dropped by $4 \%$. Both covariates were important, but the year effect appeared to have greater importance than the date effect.

The year covariate was replaced with prey abundance and environmental indices to explore the causes of inter-annual variation (the mechanism underlying the year effect). To check for colinearity between covariates, Pearson correlation coefficients were calculated pairwise for all covariates and no 2 covariates were in any 1 model if the value exceeded 0.4, since the effect of one variable would be confounded by that of the other variable (Table 1). The correlations were calculated using data from the years for which we had blubber measurements only. The correlations were tested for significance at the 1\%, $5 \%$ and $10 \%$ level. Also, VIFs were inspected to help identify colinearity (Table 2).

Table 1. Pearson's r-values for correlations between the covariates capelin Mallotus villosus, polar cod Boreogadus saida (Pcod), Atlantic cod Gadus morhua (Acod, age 3+ yr), krill Thysanoessa sp. and Meganyctiphanes norvegica, saithe Pollachius virens, haddock Melanogrammus aeglefinus, herring Clupea harrengus, the NAO index, Kola Peninsula temperature (KP temp) and the summer open water (SOW) index. Data from the years for which we had blubber thickness measurements were used when calculating the Pearson correlations. Pearson correlations $>10.4 \mid$ are shown in bold, and significance is indicated at ${ }^{\#} \mathrm{p}<0.1,{ }^{*} \mathrm{p}<0.05$ or $^{* *} \mathrm{p}<0.01$

\begin{tabular}{|c|c|c|c|c|c|c|c|c|c|c|}
\hline & Capelin & Krill & Pcod & Acod & Saithe & Haddock & Herring & NAO & KP temp & SOW \\
\hline Capelin & 1 & & & & & & & & & \\
\hline Krill & $-0.67^{*}$ & 1 & & & & & & & & \\
\hline Pcod & 0.04 & -0.12 & 1 & & & & & & & \\
\hline Acod & -0.17 & 0.25 & -0.02 & 1 & & & & & & \\
\hline Saithe & -0.50 & 0.21 & $0.79^{* *}$ & -0.12 & 1 & & & & & \\
\hline Haddock & -0.20 & 0.15 & 0.30 & $0.90^{* *}$ & 0.23 & 1 & & & & \\
\hline Herring & -0.45 & $0.69^{*}$ & 0.38 & 0.05 & 0.45 & -0.01 & 1 & & & \\
\hline NAO & 0.14 & -0.06 & -0.36 & $-0.60^{*}$ & -0.40 & $-0.84^{* *}$ & 0.20 & 1 & & \\
\hline KP temp & 0.38 & 0.16 & $0.62^{\#}$ & -0.18 & 0.26 & 0.10 & 0.58 & $0.06^{*}$ & 1 & \\
\hline SOW & -0.32 & 0.03 & 0.53 & -0.09 & 0.54 & 0.30 & 0.37 & -0.05 & 0.28 & 1 \\
\hline
\end{tabular}


Table 2. Variation inflation factors (VIFs) for all covariates before and after colinearity was removed ( 2 models). The selected threshold for the VIFs was 3 (Zuur 2012)

\begin{tabular}{|c|c|c|c|}
\hline Covariate & VIF & \multicolumn{2}{|c|}{$\begin{array}{c}\text { VIF } \\
\text { (colinearity } \\
\text { removed) }\end{array}$} \\
\hline Capelin Mallotus villosus & 2.80 & 1.00 & \\
\hline $\begin{array}{l}\text { Krill Thysanoessa sp. and } \\
\text { Meganyctiphanes norvegica }\end{array}$ & 5.22 & & 1.13 \\
\hline Polar cod Boreogadus saida & 5.70 & 1.01 & 1.04 \\
\hline Atlantic cod Gadus morhua & 4.02 & 1.01 & 1.10 \\
\hline Saithe Clupea harrengus & 6.46 & & \\
\hline Haddock Melanogrammus aeglefinus & 8.18 & & \\
\hline Herring Clupea harrengus & 3.52 & & \\
\hline NAO & 3.95 & & \\
\hline Summer open water index & 2.37 & & \\
\hline Kola Peninsula temperature & 3.41 & & \\
\hline
\end{tabular}

Strong, positive, linear correlations between polar cod and saithe ( $\mathrm{r}=0.79$ ), and between Atlantic cod and haddock ( $\mathrm{r}=0.90)$ were found. Saithe and haddock also had the highest VIF values of 6.46 and 8.18, respectively. Because of this, saithe and haddock were dropped from the model. Krill is an important resource of energy for harp seals, particularly from early summer until autumn (Nilssen et al. 2000). Due to a strong, negative, linear correlation between capelin and krill abundances (Dalpadado \& Skjoldal 1996, Eriksen \& Dalpadado 2011), these 2 covariates were not used at the same time, but models with either capelin or krill as a covariate were fitted. Our estimate of the Pearson correlation coefficient for the correlation between capelin and krill was -0.67 , with significance set at $5 \%$. Models including both capelin and herring were also avoided ( $\mathrm{r}=-0.45)$, but models using herring as a covariate were evaluated. However, during the model selection process the smoothed estimate of the herring covariate took various different shapes, depending on the covariates with which it was combined. This may indicate that the smoother for the herring covariate represented patterns that were due to other variables (Zuur et al. 2009). The total biomass covariate of Atlantic cod and the covariate containing biomass of 1- and 2-yr old Atlantic cod were not favoured by the process of model selection. Amphipods are also an important source of energy for harp seals during autumn (see Nilssen et al. 2000), but due to poor quality of the amphipod data, they were excluded from the analyses.

A strong, linear correlation between polar cod and the SOW index ( $r=0.53)$ was found, but the correlation was not significant. However, by extending
Table 3. Top candidate models for blubber thickness of the 1+ group using the covariates capelin Mallotus villosus, polar cod Boreogadus saida (pcod), Atlantic cod Gadus morhua (acod, age 3+ yr) and krill Thysanoessa sp. and Meganyctiphanes norvegica. $\triangle \mathrm{AICs}$ are the differences in the Akaike's information criterion (AIC) scores between each model and the model with the lowest AIC score. We also show evidence ratios and AIC weights. In addition to the covariates listed, each model contains an intercept term $\alpha$ and smooth terms for the covariates length s(length):sex and date s(date) (see Eq. 2). s(.): estimated functional relationship between a given covariate and blubber thickness; $\beta$ : estimated linear coefficient for a linear term

\begin{tabular}{|c|c|c|c|}
\hline Covariate & $\Delta \mathrm{AIC}$ & $\begin{array}{l}\text { Evidence } \\
\text { ratio }\end{array}$ & $\begin{array}{c}\text { AIC } \\
\text { weight }\end{array}$ \\
\hline 1. $s($ acod $)+\beta_{1}$ capelin $+\beta_{2}$ pcod & 0 & 1.0 & 0.58 \\
\hline 2. $s($ capelin $)+s($ acod $)$ & 2.13 & 2.91 & 0.20 \\
\hline 3. $s($ krill $)+s(p c o d)+s(\operatorname{acod})$ & 2.63 & 3.73 & 0.16 \\
\hline 4. $\mathrm{s}(\mathrm{krill})+\mathrm{s}(\mathrm{acod})$ & 4.36 & 8.86 & 0.07 \\
\hline 5. $s($ capelin $)+s($ pcod $)$ & 16.82 & $10^{3}$ & $10^{-4}$ \\
\hline 6. $s($ krill $)+s(p c o d)$ & 26.92 & $10^{5}$ & $10^{-7}$ \\
\hline 7. $s($ pcod $)+s($ acod $)$ & 40.36 & $10^{8}$ & $10^{-10}$ \\
\hline
\end{tabular}

the time frame when calculating the correlation, the strength of the correlation increased $(r=0.71)$ and was significant at a $1 \%$ level. The same was observed between polar cod and the Kola Peninsula temperature data $(\mathrm{r}=0.62)$. The correlation was not significant for the chosen years, but was significant at a $5 \%$ level when extending the time frame. Polar cod was therefore used as a covariate instead of either the SOW index or the Kola Peninsula temperature data. Also, the polar cod data were more complete than the SOW index data and the Kola Peninsula temperature data. Both environmental data sets were lacking observations from 2010, which was important for modelling the blubber thickness in 2011. The NAO index had a strong linear correlation with large Atlantic cod $(\mathrm{r}=-0.60)$. Atlantic cod was therefore used as a covariate, instead of the NAO index.

Table 3 shows the top model candidates for the blubber thickness of the 1+ group, ranked from best to worst, based on the AIC score. The table shows the $\triangle \mathrm{AIC}$, the evidence ratios, and the AIC weights. All the top model candidates used a time lag of $1 \mathrm{yr}$ for prey abundances and environmental variables. Models with terms calculated with time lags of 0,2 , and $3 \mathrm{yr}$ were not favoured, based on their AIC scores. Also, models that included interactions between the different prey variables were not favoured, based on their AIC scores. Three degrees of freedom for the smoothers of the biomass and environmental variables was found to be sufficient for all cases. 
One model seemed to stand out among the top candidates for blubber thickness of the 1+ group, with an AIC weight of 0.58 . This model contained the prey biomass covariates capelin, polar cod (pcod) and Atlantic cod (acod) of age 3+ and had the following structure:

$$
\begin{gathered}
\text { Blubber thickness }=40.66+s(\text { length }): \text { sex } \\
+s(\text { date })+s(\text { acod })+\beta_{1} \text { capelin }+\beta_{2} \text { pcod }
\end{gathered}
$$

Here the $\beta$ s denote the estimated linear coefficients. The model suggests that negative relationships exist between blubber thickness and capelin $\left(\beta_{1}=-1.13, \mathrm{SE}=0.13\right)$ and polar $\operatorname{cod}\left(\beta_{2}=-5.26, \mathrm{SE}\right.$ $=0.73)$. The Atlantic cod covariate was estimated to

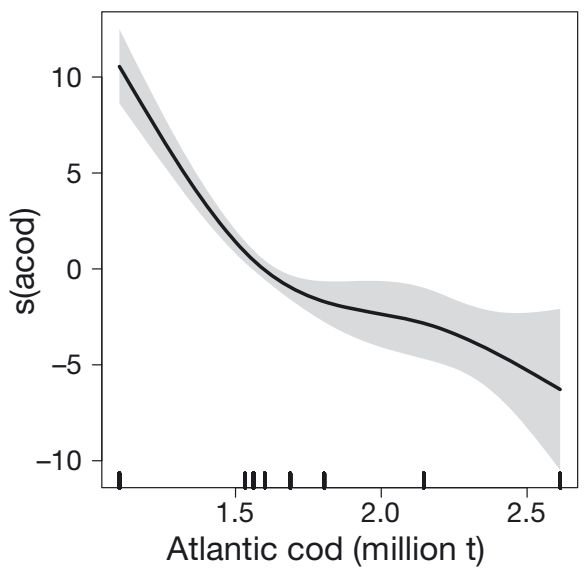

Fig. 7. Pagophilus groenlandicus. Estimated smooth function (s) showing relationship between available Atlantic cod Gadus morhua (acod) biomass and the dorsal blubber thickness of age 1+ yr harp seals taken in the southeastern Barents Sea. This is the non-linear term from the best model fit in Table 3. The other responses not shown here are linear terms. Shaded areas show the $95 \%$ confidence intervals have a non-linear relationship (edf $=7.7$ ), but the relationship had a negative trend, i.e. as Atlantic cod biomass (of age 3+) increased, blubber thickness decreased (Fig. 7). The smoothed estimates of the body length and date variables were very similar to those in Fig. 5 and are thus not repeated. The model explained $49.9 \%$ of the variation in blubber thickness of 1+ harp seals, a little higher than the model containing year (rather than prey or abiotic variables) as a covariate. No trends in the residuals were found.

The model containing krill as a covariate, instead of capelin, comes up high on the list of top candidate models with a $\triangle$ AIC of 2.63 and an AIC weight of 0.16. Fig. 8 shows the estimated relationship between the blubber thickness and the covariates krill (edf $=2.9)$, Atlantic cod (edf $=2.0)$, and polar cod (edf $=1.2$ ). A strong, positive relationship between krill abundance and blubber thickness was evident and there was a negative, linear relationship between Atlantic cod of age 3+ and polar cod with respect to blubber thickness. No trends in the residuals were found in this model either.

Predictions of the models fitted to the blubber thickness data of the 1+ group are shown in Fig. 9. The modelled blubber thickness using the model with year as a covariate is shown in blue, and the model with the lowest AIC score, containing the biomass of capelin, polar cod and Atlantic cod, is shown in red. The mean values of the length and date covariates were used when evaluating the model predictions. The $\triangle \mathrm{AIC}$ of the model containing year as a covariate and the model containing prey biomass was 11 , whereas the model containing prey biomass had the lowest AIC.
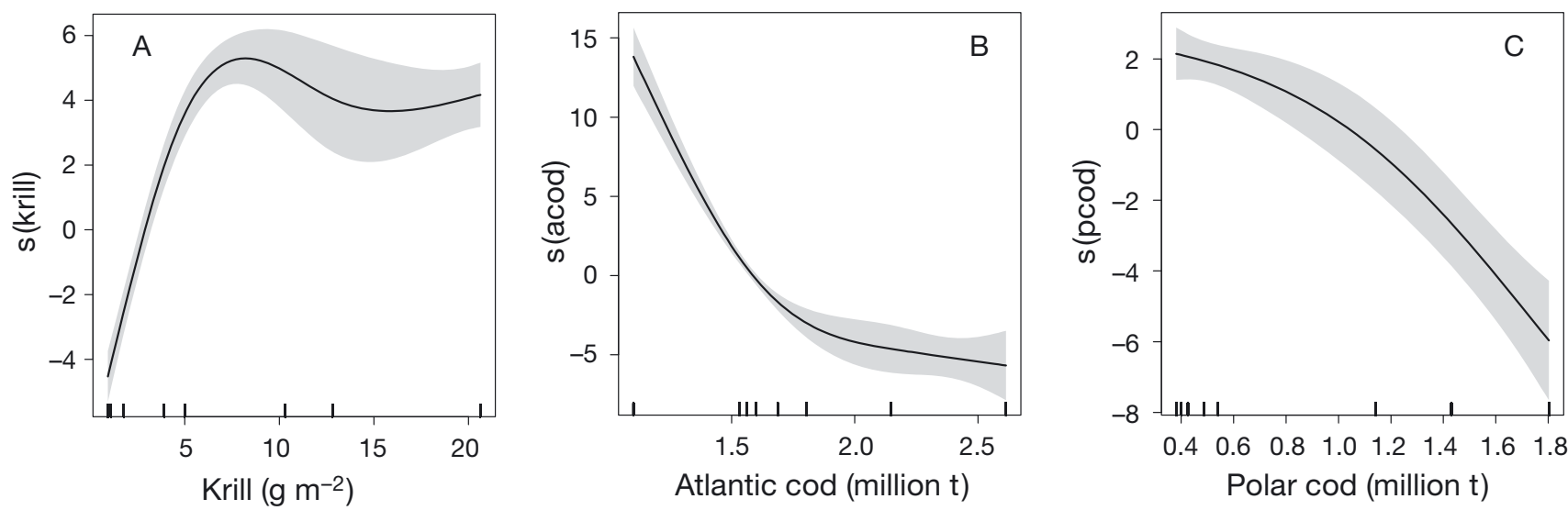

Fig. 8. Pagophilus groenlandicus. Estimated smooth functions (s) showing relationship between dorsal blubber thickness of age 1+ yr harp seals taken in the southeastern Barents Sea and available (A) krill Thysanoessa sp. and Meganyctiphanes norvegica, (B) Atlantic cod Gadus morhua (acod) and (C) polar cod Boreogadus saida (pcod) biomass. Shaded areas show the $95 \%$ confidence intervals 


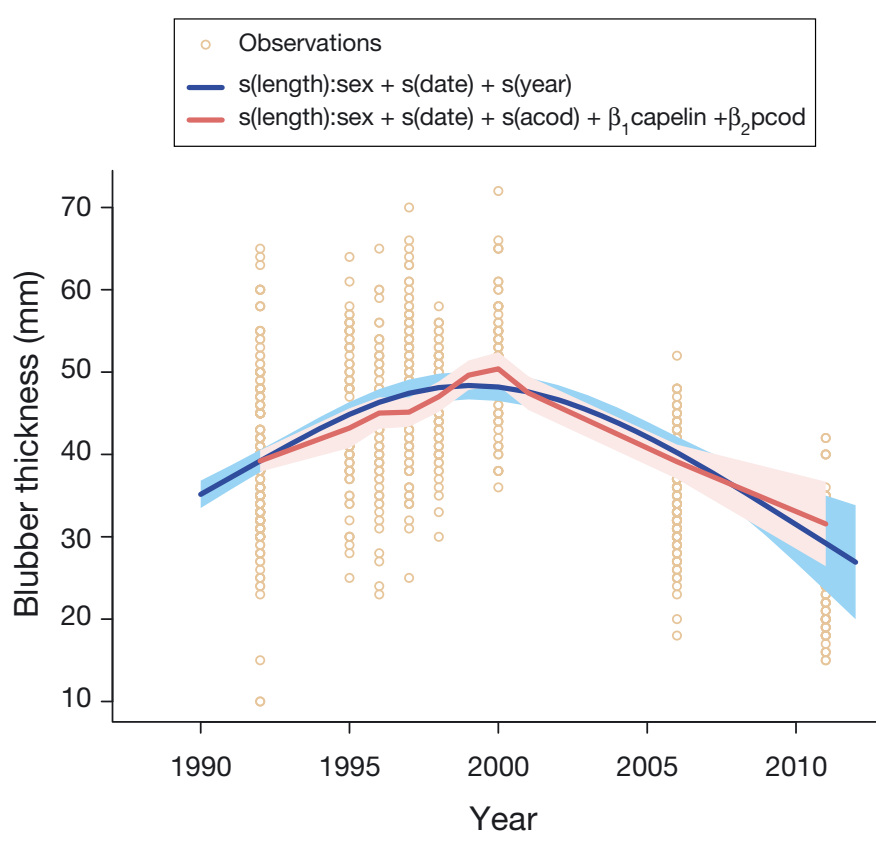

Fig. 9. Pagophilus groenlandicus. Modelled blubber thickness of the 1+ group using year as a covariate (blue) and using the covariates from the model with the lowest Akaike's information criterion (AIC) score from Table 3 (red). The $\triangle$ AIC of the 2 models is 10.09 and the model containing prey biomass data has the lowest AIC. S(.): estimated functional relationship between a given covariate and blubber thickness; $\beta$ : estimated linear coefficient for a linear term. Shaded areas show 95\% confidence intervals. Mean values of the date and length covariates are used in these model predictions

Another key aim was to investigate whether the observed decline in pup production after 2003 was associated with changes in body condition of the seals. A strong, linear correlation between the pup production estimates and the mean blubber thickness of the $1+$ group was found $(r=0.83, \mathrm{p}<0.01)$. However, the relationship did not look strictly linear, so we tried fitting a GAM. Fig. 10 shows the nonlinear fit between predicted blubber thickness of the $1+$ group, using the length-date-year model and the observed pup production estimates. For blubber thickness between 30 and $38 \mathrm{~mm}$, the GAM indicated a small decline in pup production, but due to the wide confidence intervals it was not possible to make any meaningful inferences in this range. The GAM model explained $82 \%$ of the deviance.

\section{DISCUSSION}

This study indicates that harp seal blubber thickness varied over time. For animals aged 1 yr and

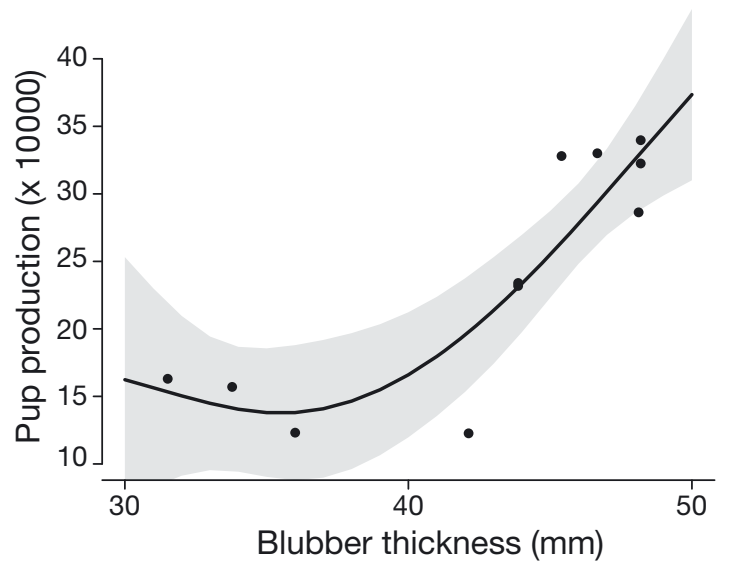

Fig. 10. Pagophilus groenlandicus. Estimated non-linear relationship between the predicted blubber thickness of the $1+$ group and the pup production estimates

older, body condition increased during the 1990s, reached a peak around 2000 and then dropped significantly to a minimum level in 2011.

There was seasonal variation in the blubber thickness of the 1+ group, consistent with the energetic expenditures involved in whelping, suckling, mating and moulting. Late March to early April is characterised by reduced loss of deposited blubber reserves, presumably due to the known feeding activity of harp seals along the Murman and Norwegian coasts after mating and before moult (see Nordøy et al. 2008).

The relationship between body length and blubber thickness was significantly different between males and females for the 1+group. For males there was a positive relationship up to about $140 \mathrm{~cm}$, after which it stabilised. For females the model displayed a positive relationship up to $140 \mathrm{~cm}$, then a negative relationship for lengths between 140 and $160 \mathrm{~cm}$, and again a positive relationship for seals longer than $160 \mathrm{~cm}$. Harp seal females attain sexual maturity at approximately $140 \mathrm{~cm}$ length (Frie et al. 2003). We suggest that the reduced condition in 140 to $160 \mathrm{~cm}$ long females is consistent with the energetic expenditures involved in pregnancy and suckling and may reflect trade-offs between the allocation of resources to growth and body condition versus reproduction (Sydeman et al. 1991). Increased condition in larger $(>160 \mathrm{~cm})$ females could indicate reduced fertility with age in harp seal females. Although there is no previous evidence for senescence in harp seals, reduced pregnancy rates with age have been reported in other pinnipeds, e.g. hooded seals (Frie et al. 2012) and grey seals (Bowen et al. 2006). Improvements in foraging skills with age and experience may also have contributed. Older females have, for exam- 
ple, been observed to exploit spawning capelin in the southeastern Barents Sea in April, i.e. between breeding and moult (Heggebakken 2005, Nordøy et al. 2008).

The condition of pups varied significantly with body length, date (here taken as days elapsed since 1 March) and year. The GAM shows that an almost linear relationship existed between body length and blubber thickness. The duration of the suckling period is evident from the increasing and subsequently decreasing blubber thickness over time. A small drop in the condition of pups seems to have prevailed around 1997 to 1998 . This may indicate some environmental event that had a significant impact, e.g. the pups may have been weaned early due to factors such as early ice breakup or females may have been unable to deliver enough nutrition. During the massive harp seal invasions into Norwegian waters from 1986 to 1988 (Haug \& Nilssen 1995), harp seal pups were observed to have particularly low body weight in the whelping areas in the White Sea (Timoshenko 1995). The 1997-1998 period does not coincide with an invasion period and there is no evidence for reduced condition in adult seals in this period. It is, however, interesting to note that the abundance of both krill and capelin was very low from 1996 to 1998 (Eriksen \& Dalpadado 2011).

In order to fully separate the response of date and year, samples for the full seasonal range are required for all years. Due to lack of full temporal overlap between sampled blubber thickness between years, it is possible that the date and the year variables were confounded. Simulation examples were constructed to explore this, but none of them showed any indications that a confounding effect was present (see the Supplement at www.int-res.com/articles/ suppl/m484p287_supp.pdf). We believe it is unlikely that the low blubber thickness observed in 2006 and 2011 is a sampling artifact.

The inter-annual variation in harp seal body condition was best explained by the biomass of capelin, Atlantic cod (age 3+) and polar cod, with a time lag of $1 \mathrm{yr}$. Thus, the harp seal body condition from March to May depended mainly on the foraging success of the previous year. Due to strong linear correlations with prey biomass covariates, the environmental variables were redundant when modelling the blubber thickness using prey covariates and, furthermore, models containing prey, rather than environmental covariates, were favoured. This suggests that the impact of environmental variation on harp seals (high trophic level predators) is mainly mediated through the effects of that variation on prey.
As well as being food for the harp seals, fish act as competitors for shared resources, particularly macrozooplankton (see Bogstad et al. 2000, Wassmann et al. 2006). These macro-zooplankton (krill and amphipods) appear to play an important role for the seals during summer and autumn when their feeding needs are high (e.g. Lindstrøm et al. 1998, 2013, Nilssen et al. 2000). The negative relationships between harp seal body condition and biomasses of capelin, polar cod and Atlantic cod suggest that the competitive effect for shared prey resources dominates for these species. Unfortunately, we were not able to analyse the relationship between harp seals and pelagic amphipods directly, due to lack of data on amphipod abundance. However, given previous ecological studies, where amphipods were found to be the prime prey species during late summer (Nilssen et al. 1995b), it seems likely that harp seal body condition increases with increasing amphipod biomass.

Capelin is the largest pelagic stock, and in some years their biomass can amount to 4-7 million $t$, which can result in major mortality of krill (Eriksen \& Dalpadado 2011). Due to the strong, negative, linear relationship between capelin and krill (Eriksen \& Dalpadado 2011), it seems likely that a strong, positive relationship exists between krill abundance and seal blubber thickness. Among the candidate models, the model containing krill instead of capelin came up high and the strong, positive relationship between krill abundance and blubber thickness was evident. It is to be expected that the negative effects of competing species would be picked up by this model, even if the abundance of krill was included explicitly. This is because all quantities were measured on an annual basis. Therefore, for a given krill abundance, seal foraging will be less successful if competitors are abundant, due to prey depletion (removals or production or biomass that would otherwise be available to the seals) over the course of the year.

This study confirms previous ecological studies in that harp seal foraging success and thus body condition depend on changes in prey availability (Haug \& Nilssen 1995, Nilssen et al. 1997). During the massive harp seal invasions, primarily of East Ice seals, to the coast of Norway between 1986 and 1988, the seals were reported to be in very poor condition (Nilssen et al. 1997). In the White Sea the pups were observed to have significantly lower mean weights in these years, compared to previous and subsequent years (Timoshenko 1995). Haug \& Nilssen (1995) suggested that the invasions resulted from food shortage during 
their southern migration, due to low abundance of 3 key pelagic forage fish species: capelin, herring and polar cod. It should be emphasised that the resource situation in the mid-1980s was a very unique scenario: this was the only occasion, since monitoring of Barents Sea fish stocks started in the 1970s, that all pelagic fish stocks have been at a minimum level simultaneously (see Gjøsæter et al. 2009a).

The predator-prey relationships in the Barents Sea between capelin, juvenile herring and Atlantic cod (e.g. Hamre 1994, Gjøsæter \& Bogstad 1998, Hjermann et al. 2007, Lindstrøm et al. 2009) and between capelin and krill (Dalpadado \& Skjoldal 1996, Eriksen \& Dalpadado 2011) are well documented. Historic data show that the pelagic fish stocks (capelin, juvenile herring and polar cod) in the Barents Sea fluctuated dramatically during the past $40 \mathrm{yr}$, with decadal periodicities. Generally, a high abundance of juvenile herring is followed by a low capelin abundance, whereas a high capelin abundance is followed by a low krill abundance. The population of polar cod, which appears to be more decoupled from the pelagic system, fluctuated a lot since the 1980s, but has shown a slow increase from a very low level in the late 1980s to 2011.

Despite the fluctuations in stock dynamics of prey species (inferred from previous diet studies), it appears that harp seal food availability has improved in the Barents Sea during the 1990s, compared to the late 1980s. Nilssen et al. (1998) reported a smaller harp seal invasion in 1995; nevertheless, the body condition observed for seals in 1995 was higher than in 2006 and 2011. The current analyses suggest stable or even improved condition of harp seals for the period 1997-2001, a period which was characterised by high abundance of pelagic fish and low abundance of krill (Gjøsæter et al. 2009a). According to Gjøsæter et al. (2009a), the period after 2006 was characterised by a new collapse in the capelin stock, whereas the abundance of both polar cod and herring were high. Currently, the abundance of polar cod seems to be high and the capelin stock size has improved substantially in the last 2 yr (Gjøsæter et al. 2009b).

Relationships have been observed between body condition, abiotic and biotic variables, and fertility also in other systems/predators, e.g. long term fluctuations in body condition were observed in harp seals in the NW Atlantic, where adult seals particularly were in poorer condition in the early 1990s than in the mid-1980s (Chabot et al. 1996). This decrease in condition was paralleled by a decrease in pregnancy rate and an increase in the mean age of maturity in females. Another Barents Sea top predator, the common minke whale Balaenoptera acutorostrata, has been observed to be in poor condition in years with low habitat quality (insufficient availability of herring and capelin; Haug et al. 2002), whereas Antarctic minke whales $B$. bonarensis have exhibited a prevailing decrease in body condition over nearly 2 decades (Konishi et al. 2008). This is presumably due to a combination of reduced krill availability and/or increased abundance of krill feeders other than minke whales in the area (e.g. Mori \& Butterworth 2006). Comparable findings in Weddell seals (Proffitt et al. 2007a,b, Garrott et al. 2012) showed that body condition variations can be connected to abiotic variables and that body condition subsequently affects the incidence of pupping, pupping success and recruitment.

Top-down effects are well known; for example, generalists can dampen or eliminate cyclical interactions between specialist predators and their prey (Hanski et al. 1991), as well as cause predator pits (Hilborn \& Walters 1992). In contrast, the dynamics of generalist predators are not usually considered to be closely coupled to the dynamics of their prey (e.g. Hanski et al. 1991, Murdoch et al. 2002). This study shows that harp seals respond to changes in prey biomass, although the nature of this response may be rather complex and unexpected, i.e. there can be a negative relationship between the foraging success of a predator and the abundance of one or more of its prey. We argue that such 'confusion' is to be expected in a marine ecosystem with a food web that contains multiple trophic links and the potential for indirect effects (Yodzis 2001). This points to the importance of considering the multi-species context very carefully when the aim is to manage ecosystems for the best sustainable fisheries yield, while also taking account of apex predator species, both as competitors with fisheries (Matthiopoulos et al. 2008) and as dependent species that we may wish to conserve (Frederiksen et al. 2004).

Recent Russian aerial surveys to assess pup production of the Barents Sea stock of harp seals indicate a sudden decline in pup production after 2003 (ICES 2011a). Although the question is still unresolved, ICES (2011a) suggested the most likely explanation for the observed change in pup production to be reduced female fertility. Interestingly, the current body condition measurements of seals belonging to this stock after 2003 (in 2006 and 2011) were significantly lower than similar measurements conducted before the pup production declined (1992 to 2000). The current study demonstrated a positive correlation between pup abundance and blubber thick- 
ness, suggesting that the observed decline in pup production after 2003 might be attributed to changes in body condition of the seals. This may be an indication of insufficient availability of appropriate food for the seals in recent years, leading to a sequence of events, including food shortage, poor body condition, reduced pregnancy rates and reduced pup production by the seal population. In this analysis we assume that condition after pupping is related to condition prior to pupping. Inter-annual variations in pup production in other pinnipeds are related to food shortage and poor body condition (see McKenzie et al. 2005).

The effects of removals by top predators have been included in models of marine ecosystems. This could lead to an improved understanding of the true effects of predators on the system they inhabit, i.e. the topdown effects of predators, such as the effects of seals on their prey. However, it has generally proved very difficult to quantify the bottom-up effects of prey abundance on predators and therefore, such effects are usually not included in multi-species models, even where quite complex trophic interactions are considered. In this study, we developed a framework for quantifying the effects of prey on the body condition and population dynamics of a top predator. Such a framework has the potential to improve multispecies models with the inclusion of such bottom-up effects and to improve the management of the harvesting of both fish and marine mammal populations.

Acknowledgements. We thank N. E. Skavberg, M. Poltermann, L. Heggebakken, C. das Neves, L. S. Pettersen, S. Magnussen, L. Lindblom and other persons who took part in the surveys aimed to collect the biological data. We thank Dr. A. Zuur at Highland Statistics for helpful comments during the writing of this manuscript. We thank the reviewers for the careful reading of the manuscript and constructive comments that have helped to improve it.

\section{LITERATURE CITED}

Anderson DR (2008) Model based inference in the life sciences: a primer on evidence. Springer-Verlag, New York, NY

Bogstad B, Haug T, Mehl S (2000) Who eats whom in the Barents Sea? NAMMCO Sci Publ 2:98-119

Bogstad B, Dingsør GE, Gjøsæter H, Ingvaldsen R (2013) Changes in the relations between oceanographic conditions and recruitment of cod, haddock and herring in the Barents Sea. Mar Biol Res (in press)

Bowen WD, Iverson SJ, McMillan JI, Boness DJ (2006) Reproductive performance in grey seals: age-related improvement and senescence in a capital breeder. J Anim Ecol 75:1340-1351
Burnham KP, Anderson DR (2002) Model selection and inference: a practical information-theoretic approach, 2nd edn. Springer-Verlag, New York, NY

Chabot D, Stenson GB, Cadigan NG (1996) Short- and longterm fluctuations in the size and condition of harp seal (Phoca groenlandica) in the Northwest Atlantic. NAFO Sci Counc Stud 26:15-32

> Dalpadado P, Skjoldal HR (1996) Abundance, maturity and growth of the krill species Thysanoessa inermis and $T$. longicaudata in the Barents Sea. Mar Ecol Prog Ser 144: 175-183

Dippner JW, Ottersen G (2001) Cod and climate variability in the Barents Sea. Clim Res 17:73-82

Eriksen E, Dalpadado P (2011) Long-term changes in Krill biomass and distribution in the Barents Sea: Are the changes mainly related to capelin stock size and temperature conditions? Polar Biol 34:1399-1409

Frederiksen M, Wanless S, Harris MP, Rothery P, Wilson LJ (2004) The role of industrial fisheries and oceanographic change in the decline of North Sea black-legged kittiwakes. J Appl Ecol 41:1129-1139

Frie AK, Potelov VA, Kingsley MCS, Haug T (2003) Trends in age at maturity and growth parameters of female northeast Atlantic harp seals, Pagophilus groenlandicus. ICES J Mar Sci 60:1018-1032

Frie AK, Stenson GB, Haug T (2012) Long-term trends in reproductive and demographic parameters of female Northwest Atlantic hooded seals (Cystophora cristata): population responses to ecosystem change? Can J Zool 90:376-392

Garrott RA, Rotella JJ, Siniff DB, Parkinson CL, Stauffer GE (2012) Environmental variation and cohort effects in an Antarctic predator. Oikos 121:1027-1040

Gjøsæter H, Bogstad B (1998) Effects of the presence of herring (Clupea harengus) on the stock-recruitment relationship of Barents Sea capelin (Mallotus villosus). Fish Res 38:57-71

> Gjøsæter H, Bogstad B, Tjelmeland S (2009a) Ecosystem effects of the three capelin stock collapses in the Barents Sea. Mar Biol Res 5:40-53

Gjøsæter H, Dommasnes A, Falkenhaug T, Hauge M, Johannesen E, Olsen E, Skagseth $\varnothing$ (eds) (2009b) Havets ressurser og miljø 2009. Fisken Hav Særnr 1-2009. Institute of Marine Research, Tromsø

> Halpern BS, Walbridge S, Selkoe KA, Kappel CV and others (2008) A global map of human impact on marine ecosystems. Science 319:948-952

> Hamre J (1994) Biodiversity and exploitation of the main fish stocks in the Norwegian-Barents Sea ecosystem. Biodivers Conserv 3:473-492

> Hanski I, Hansson L, Henttonen H (1991) Specialist predators, generalist predators, and the microtine rodent cycle. J Anim Ecol 60:353-367

Harrell F (2012) Hmisc: Harrell Miscellaneous. R package version 3.9-3. Available at http://CRAN.R-project.org/ package $=$ Hmisc

Haug T, Nilssen KT (1995) Ecological implications of harp seal (Phoca groenlandica) invasions in northern Norway. In: Blix AS, Walløe L, Ulltang $\varnothing$ (eds) Whales, seals, fish, and man. Elsevier Science, Amsterdam, p 545-556

Haug T, Lindstrøm U, Nilssen KT (2002) Variations in minke whale (Balaenoptera acutorostrata) diet and body condition in response to ecosystem changes in the Barents Sea. Sarsia 87:409-422 
Heggebakken L (2005). Hvorfor invaderer grønlandssel deler av norskekysten om våren. MSc dissertation, University of Tromsø

Hilborn R, Walters C (1992) Quantitative fisheries stock assessment: choice, dynamics and uncertainty. Chapman \& Hall, New York, NY

Hjermann DØ, Bogstad B, Eikeset AM, Ottersen G, Gjøsæter H, Stenseth NC (2007) Food web dynamics affect Northeast Arctic cod recruitment. Proc R Soc Lond B Biol Sci 274:661-669

Hurrell JW, Deser C (2010) North-Atlantic climate variability: the role of the North Atlantic Oscillation. J Mar Syst 79:231-244

ICES (2010) Report of the Working Group on Widely Distributed Stocks, 28 August-3 September 2010, Vigo, Spain. ICES CM 2010/ACOM 15

ICES (2011a) Report of the Working Group on Harp and Hooded Seals, 15-19 August 2011, St. Andrews, Scotland, UK. ICES CM 2011/ACOM 22

ICES (2011b) Report of the Arctic Fisheries Working Group, 28 April-4 May 2011, Hamburg, Germany. ICES CM 2011/ACOM 05

Johannesen E, Ingvaldsen RB, Bogstad B, Dalpadado P and others (2012) Changes in Barents Sea ecosystem state, 1970-2009: climate fluctuations, human impact, and trophic interactions. ICES J Mar Sci 69:860-889

> Johnson JB, Omland KS (2004) Model selection in ecology and evolution. Trends Ecol Evol 19:101-108

Konishi K, Tamura T, Zenitani R, Bando T, Kato H, Walløe L (2008) Decline in energy storage in the Antarctic minke whale (Balaenoptera bonarensis) in the Southern Ocean. Polar Biol 31:1509-1520

Kovacs KM, Haug T, Lydersen C (2009) Marine mammals of the Barents Sea. In: Sakshaug E, Johnsen G, Kovacs K (eds) Ecosystem Barents Sea. Tapir Academic Press, Trondheim, p 453-496

Lamb PJ, Peppler RA (1987) North Atlantic Oscillation: concept and an application. Bull Am Meteorol Soc 68: $1218-1225$

Lindstrøm U, Harbitz A, Haug T, Nilssen KT (1998) Do harp seals Phoca groenlandica exhibit particular prey preferences? ICES J Mar Sci 55:941-953

Lindstrøm U, Smout S, Howell D, Bogstad B (2009) Modelling multi-species interactions in the Barents Sea ecosystem with special emphasis on minke whales and their interactions with cod, herring and capelin. Deep-Sea Res II 56:2068-2079

Lindstrøm U, Nilssen KT, Pettersen LMS, Haug T (2013) Harp seal foraging behaviour during summer around Svalbard in the northern Barents Sea: diet composition and selection of prey. Polar Biol 36:305-320

Loeng H, Ozhigin V, Ådlandsvik B (1997) Water fluxes through the Barents Sea. ICES J Mar Sci 54:310-317

Lydersen C, Angantyr LA, Wiig Ø, Øritsland T (1991) Feeding habits of Northeast Atlantic harp seals (Phoca groenlandica) along the summer ice edge of the Barents Sea. Can J Fish Aquat Sci 48:2180-2183

> Matthiopoulos J, Smout S, Winship AJ, Thompson D, Boyd IL, Harwood J (2008) Getting beneath the surface of marine mammal-fisheries competition. Mammal Rev 38: 167-188

McKenzie J, Parry LJ, Page B, Goldsworthy SD (2005) Estimation of pregnancy rates and reproductive failure in New Zealand fur seals (Arctocephalus forsteri). J Mammal 86:1237-1246
Mori M, Butterworth DS (2006) A first step towards modelling the krill-predator dynamics of the Antarctic ecosystem. CCAMLR Sci 13:217-277

Murdoch WW, Kendall BE, Nisbet RM, Briggs CJ, McCauley E, Bolser R (2002) Single-species models for manyspecies food webs. Nature 417:541-543

Nakken O (1994) Causes of trends and fluctuations in the Arcto-Norwegian cod stock. ICES Mar Sci Symp 198: 212-228

> Nilssen KT, Haug T, Potelov V, Stasenkov VA, Timoshenko YK (1995a) Food habits of harp seals (Phoca groenlandica) during lactation and moult in March-May in the southern Barents Sea and White Sea. ICES J Mar Sci 52: 33-41

> Nilssen KT, Haug T, Potelov V, Timoshenko YK (1995b) Feeding habits of harp seals (Phoca groenlandica) during early summer and autumn in the northern Barents Sea. Polar Biol 15:485-493

Nilssen KT, Haug T, Grotnes PE, Potelov V (1997) Seasonal variation in body condition of adult Barents Sea harp seals (Phoca groenlandica). J Northwest Atl Fish Sci 22: $17-25$

Nilssen KT, Haug T, Øritsland T, Lindblom L, Kjellqwist SA (1998) Invasions of harp seals Phoca groenlandica Erxleben to coastal waters of Norway in 1995: ecological and demographic implications. Sarsia 83:337-345

Nilssen KT, Pedersen OP, Folkow L, Haug T (2000) Food consumption estimates of Barents Sea harp seals. NAMMCO Sci Publ 2:9-28

> Nilssen KT, Haug T, Lindblom C (2001) Diet of weaned pups and seasonal variations in body condition of juvenile Barents Sea harp seals Phoca groenlandica. Mar Mamm Sci 17:926-936

Nordøy ES, Folkow LP, Potelov V, Prischemikhin V, Blix AS (2008) Seasonal distribution and dive behaviour of harp seals (Pagophilus groenlandicus) of the White SeaBarents Sea stock. Polar Biol 31:1119-1135

> Ottersen G, Sundby S (1995) Effects of temperature, wind and spawning stock biomass on recruitment of ArctoNorwegian cod. Fish Oceanogr 4:278-292

Ottersen G, Loeng H, Raknes A (1994) Influence of temperature variability on recruitment of cod in the Barents Sea. ICES Mar Sci Symp 198:471-481

Ozhigin VK, Ingvaldsen RB, Loeng H, Boitsov VD, Karsakov MS (2011) The Barents Sea. In: Jakobsen T, Ozhigin VK (eds) The Barents Sea. Ecosystem, management, resources. Half a century of Russian-Norwegian cooperation. Tapir Academic Press, Trondheim, p 39-76

Proffitt KM, Garrott RA, Rotella JJ, Siniff DB, Testa JW (2007a) Exploring linkages between abiotic oceanographic processes and a top-trophic predator in an Antarctic ecosystem. Ecosystems 10:120-127

> Proffitt KM, Garrott RA, Rotella JJ, Wheatley KE (2007b) Environmental and senescent related variations in Weddell seal body mass: implications for age-specific reproductive performance. Oikos 116:1683-1690

Ritz C, Spiess AN (2008) qpcR: an R package for sigmoidal model selection in quantitative real-time polymerase chain reaction analysis. Bioinformatics 24:1549-1551

Ruppert D, Wand MP, Carroll RJ (2003) Semiparametric regression. Cambridge University Press, Cambridge

Skagseth $\varnothing$, Furevik $T$, Ingvaldsen $R$, Loeng $H$, Mork KA, Orvik KA, Ozhighin V (2008) Volume and heat transport to the Arctic via the Norwegian and Barents Seas. In: Dickson RR, Meinke J, Rhines P (eds) Arctic-Subarctic 
ocean fluxes: Defining the role of the northern seas in climate. Springer, Dordrecht p 45-64

Sorteberg A, Kvingedal B (2006) Atmospheric forcing on the Barents Sea winter ice extent. J Clim 19:4772-4784

Sydeman WJ, Huber HR, Emslie SD, Ribic CA, Nur N (1991) Age-specific weaning success of northern Elephant Seals in relation to previous breeding experience. Ecology 72 : 2204-2217

Timoshenko YK (1995) Harp seals as indicators of the Barents Sea ecosystem. In: Blix AS, Walløe L, Ulltang Ø (eds) Whales, seals, fish, and man. Elsevier Science, Amsterdam, p 509-523

Wassmann P, Reigstad M, Haug T, Rudels B and others (2006) Food webs and carbon flux in the Barents Sea. Prog Oceanogr 71:232-287

Editorial responsibility: Hans Heinrich Janssen, Oldendorf/Luhe, Germany
Wood SN (2004) Stable and efficient multiple smoothing parameter estimation for generalized additive models. J Am Stat Assoc 99:673-686

Wood SN (2006) Generalized additive models: an introduction with R. Chapman \& Hall, New York, NY

Yodzis P (2001) Must top predators be culled for the sake of fisheries? Trends Ecol Evol 16:78-84

Zuur AF (2012) A beginner's guide to generalized additive models with R. Highland Statistics, Newburgh

Zuur AF, Ieno EN, Walker NJ, Saveliev AA, Smith GM (2009) Mixed effects models and extensions in ecology with R. Springer, New York, NY

Zuur AF, Ieno EN, Elphick CS (2010) A protocol for data exploration to avoiding common statistical problems. Methods Ecol Evol 1:3-14

Submitted: June 18, 2012; Accepted: January 21, 2013

Proofs received from author(s): May 21, 2013 